\title{
HERÓIS OU ROBOTS? \\ DESAFIOS À CIDADANIA \\ NA SOCIEDADE DA INFORMAÇÃO. \\ Para uma Teorização Histórico-Constitucional \\ Prospetiva ${ }^{1}$
}

\section{HEROES OR ROBOTS? \\ CHALLENGES TO CITIZENSHIP \\ IN THE INFORMATION SOCIETY. \\ Elements for an Historical-Constitutional Prospective \\ Theorization}

\author{
Paulo Ferreira da Cunha \\ Faculdade de Direito da Universidade do Porto
}

\begin{abstract}
Sumário: I. CONCEITOS E PRECONCEITOS JUSPOLÍTICOS NA SOCIEDADE INFORMACIONAL. II.QUESTÕES CONSTITUCIONAIS, CONCEITUAIS E HISTÓRICAS: 2.1.Chefes, heróis, salvadores: substitutos da Cidadania. 2.2. $O$ Constitucional. 2.3. Os Chefes. 2.4. Politicos e Estadistas. III.TEMPOS E TEMAS: 3.1. Delimitação Temporal. 3.2. Delimitação do objeto. 3.3. Antiheróis? 3.4.Carisma e Irracionalidade na Sociedade da Informação.
\end{abstract}

Resumo: Parece haver hodiernamente alguma esquizofrenia jurídica e política. Se por um lado se apregoa o Estado Constitucional, Estado de Direito, democrático, social, cultural, etc., por outro se diz que estamos numa sociedade de informação, como sinónimo da própria contemporaneidade, e não pouco autorizadas vozes a identificam com menos democracia e de algum modo um exílio ou subalternização da Constituição, que parece até supérflua, ante o poder magnífico da técnica. Nestas circunstâncias contraditórias, que pluralismo é possivel, e que lideranças serão engendradas?

Abstract: It seems to be in our times some legal and political schizophrenia. On the one hand is proclaimed the constitutional state, the rule of law, democratic, social, cultural state, etc., on the other it is said that we are in an information society, as synonymous of the contemporary, and some authoritative voices identify that paradigm with less democracy and somehow exile or subordination of the Constitution, which seems even superfluous before the magnificent technical power. Under these contradictory circumstances, is pluralism still is possible, and what kind of leaders will be engendered?

1 Poderão notar-se em alguns passos deste artigo intertextualidades com outros textos do autor. Contudo ele tem, no seu conjunto, vida própria, especialmente por uma focalização na sociedade da informação e nos perigos fundamentalistas, seus paradoxais mas reais contemporâneos. Além disso, é natural que seja refundido e reutilizado em livro do autor, numa e noutra das margens do Atlântico. 
Palavras-Chave: História Constitucional, Chefe, Estado Constitucional, Liderança, Pluralismo, Sociedade da Informação

Key words: Constitutional history, Chief, Constitutional State, Leadership, Pluralism, Information Society.

“(...) não havendo mais autoridade e não havendo mais decisões a tomar, que sentido terá na sociedade telemática emergente falar-se em governo, em poder, já que tal sociedade será dominada pela imagem? Qual será a estrutura político-administrativa de tal sociedade?" .

Vilém Flusser

\section{CONCEITOS E PRECONCEITOS JUSPOLÍTICOS NA SOCIEDADE INFORMACIONAL}

Há alguns desafios hodiernos a ter muito em conta na história constitucional hodierna, que ao mesmo tempo possuem e não possuem precedentes na História Constitucional (e politica) passada. Os desafios são de indole ideológica e tecnológica. E da sua tensão e conjunção não poucos problemas surgem.

Não é verdade que a tecnologia ou a panótica informação e a informatização sejam avessas à ideologia. Isso foram fumos (eles mesmos não alheios à ideologia) de um tempo não distante, mas superado e que hoje já não conseguem iludir: estão patentes as clivagens ideológicas: everything old is new again ${ }^{2}$. Pelo contrário, há evidentemente e com uma enorme força (desde logo de discurso legitimador e fonte de ilusão), uma ideologia tecnocrática, de há muito identificada, e quanto mais as técnicas se vão expandindo e, associadas ao consumismo, podem ser Ersatz de revolução ou de descontentamento, mais água vai sendo levada ao moinho da ideologia tecnocrática. Hoje, informacional, prevalentemente.

A própria expressão, hoje já um tanto em desuso, de demotecnocracia era um híbrido que correspondia a um discurso legitimador ${ }^{3}$ de um pretenso eficientismo, ou "meritocracia" que em grande medida procura fórmulas muito mitigadas ou musculadas de verdadeira representatividade e pluralismo.

A informação e mega poder informático também engendram as suas equivalências ideológicas, ao ponto de profundas transformações na política

2 Sobre ideologia, válido para as grandes linhas, mas apesar de tudo já algo desatualizado no detalhe, Paulo Ferreira da Cunha, Repensar a Politica. Ciência \& Ideologia, 2. ${ }^{a}$ ed., Coimbra, Almedina, 2007.

3 Sobre este conceito, clássico é o livro de João Baptista Machado, Introdução ao Direito e ao Discurso Legitimador, reimp., Coimbra, Almedina, 1985. 
serem vaticinadas por alguns estudiosos da matéria. Um dos mais interessantes "profetas" nesta área é o filósofo brasileiro de origem checa Vilém Flusser4.

Há alguns que não suportam que se fale nela (porque isso seria revelar o seu segredo: e falar dela é denunciá-la, expô-la); mas a verdade é que a ideologia é muito real, efetiva, e poderosa. A criação de uma ilusão que leva a que as pessoas ideologicamente formatadas (pelos diversos aparelhos ideológicos ${ }^{5}$, desde o berço) acreditem (ainda que para alguns seja uma crença numa grande farsa), e até concorram para ela, e mesmo sonhem, é uma força prodigiosa. E quando se procura fazer tirar o sonâmbulo da sua caverna, ele insiste que ela é o Mundo real e que o cá fora é utopia e sonho. Como alguns acariciam os seus grilhões!... dirá então o anti-ideólogo, que dificilmente (essa uma das grandes dificuldades: desconstruir o desconstrutor) não professará uma qualquer forma (espontânea e ingénua, certamente) de ideologia...

Ainda pior que o juizo ideológico, que depende da cor do céu terrestre (afinal a utopia) de cada um, é o julgamento moral e intelectual sobre uma medida, sobre um estilo, sobre uma pose de poder, sobre a capacidade de discernimento seja a que nivel for: do homem todo-poderoso do carimbo ao Papa dos Papas, ao Imperador dos Imperadores. Papini dizia que o que menos suportamos é que nos considerem estúpidos. E contudo (ou et pour cause?) fez o elogio da nesciência.

O problema não é, como sabemos hoje pelos estudos sobre a "inteligência emocional", de louvar a morte e calcar aos pés a inteligência, como no tempo de Miguel de Unamuno. O problema parece ser a substituição muito generalizada da inteligência dos animais politicos (para não citar portugueses, e apenas referir a Europa e não muito antigos: Churchill, De Gaulle, Adenauer, Mitterrand, etc.) por uma outra coisa, que mais parece oportunismo de sobrevivência, nuns, e teimosia obstinada apenas, noutros.

A força do preconceito é tão grande, que foi infiltrar-se na consciência dos que achavam ser contra si, e desabrochou em novo preconceito, animado da falsa consciência (ideologia) do antipreconceito. É preciso muito sentido crítico e discernimento para ver os novos preconceitos. Eles impregnam o politicamente correto $^{6}$. E o politicamente correto é a primeira das censuras ao pensamento e à sua expressão, hoje. É perigoso pensar-se, hoje. Pelos novos preconceitos absurdos (mas pseudo-racionais) de um faciosismo que se não vê ao espelho, e grita a sua pseudoverdade com vontade de a impor por toda a força a todos. E pelos velhos preconceitos mais ou menos cheios de teias de aranha, mitificados, dos obscurantismos que os primeiros preconceitos não conseguiram realmente ultrapassar de forma inteligente, e despreconceituosa...

4 Especialmente in (mas não só neste livro, longe disso): Vilém Flusser, O Universo das Imagens Técnicas. Elogio da Superficialidade, Revisão técnica de Gustavo Bernardo, São Paulo, Annablume, 2008.

5 Uma obra relativamente clássica é Louis Althusser, Idéologie et apareils idéologiques d'Etat, La Pensée, trad. port. de Joaquim José de Moura Ramos, Ideologia e Aparelhos Ideológicos do Estado, Lisboa, Presença, 1974.

6 Henri Beard / Christopher Cerf, Dicionário do Politicamente correto, trad. bras. de Vra Karam e Sérgio Karam, Introdução de Moacyr Scliar, Porto Alegre, L\&PM, 1994 e Paulo Ferreira da Cunha, Miragens do Direito. O Direito, as Instituições e o Politicamente Correto, Campinas, SP, Millennium, 2003. 
Não é fácil distinguir o tópico acriticamente aceite como verdade intocável, sendo contudo um apriorismo, um dogmatismo, e aquela verdade, ou aproximação à verdade, que se foi decantando e acaba por ser muito generalizadamente aceite, pelo bom senso. Só o bom senso, o sentido crítico (até um certo ácido crítico e mesmo cínico pode fazer falta ${ }^{7}$ ) e a experiência, o teste das teorias e das teses em situações reais permitem desfazer os preconceitos ${ }^{8} .$.

Quando se chega a discutir uma qualquer coisa miúda, de baixa, pedestre, política da hora, esquecemo-nos que por detrás da opinião-reflexo-condicionado estão várias condicionantes: desde logo, a carteira de cada um e o respetivo conteúdo; o acúmulo de triunfos e frustrações durante a vida; a infância, a escola, o berço, e não se sabe ainda quantas gerações para trás de choro ou de riso (lembrando uma dicotomia de Agostinho da Silva9), e ainda as leituras, os amigos, os conceitos e sobretudo os preconceitos, que às vezes se escondem por detrás do que julgamos ser ciência, ou realidade, ou ideais.

Não se passam as coisas para a política muito diferentemente do que ocorrem para a Economia, como lembrou Keynes ${ }^{10}$, aliás.

Os males engendram também remédios, cuja venda alimenta a imparável máquina do consumo e da produção. Um dos remédios da moderna azáfama e alienação é a chamada "auto-ajuda". Mas ela necessita também de análise e descontrução.

Tememos que muitos dos estribilhos de autoajuda e que procuram dar ânimo às pessoas que se encontram "na mó de baixo" da vida sejam apenas um paliativo das "da mó de cima" para que as demais não encontrem as escadas de acesso... "Pobre, pero honrado"... Mas uma é verdadeira: "O dinheiro não traz felicidade". Não disseram foi que a sua falta é, como dizia Rabelais, "douleur non pareille".

A tudo vai enquadrando uma música de fundo que mais é a omnipresença (como em Fahrenheit) de uma enorme tela televisiva ou de computador (ou ambas, intermutáveis), perante a qual (e a interacção sonâmbulo com a qual) tudo o resto tende a esvair-se, esmaecer, apagar-se... E por isso, no limite, poderá ser o fim da cidadania, embora por vezes apresentada como fim do próprio governo (mas não acreditemos que "le monde va de lui-même" agora pela mão de simples computadores que nos governariam servilmente e inteligentemente, poupando-nos a angústia das decisões).

7 Cf. Oliver Wendell Holmes, The Path of Law, 1897, trad. cast. de E. A. Ruso, La Senda del Derecho, máx. pp. 18-21.

8 Cf. as trinta teses sobre interpretação da experiência hermenêutica in Richard E. Palmer, Hermeneutics - Interpretation Theory in Schleiermacher, Dilthey, Heidegger and Gadamer, Northwestern University Press, 1969, trad. port. de Maria Luísa Ribeiro Ferreira, Hermenêutica, Lisboa, Edições 70, 1986, p. 243 ss..

9 Agostinho da Silva, "A Justiça”, in Diário de Alcestes, nova ed., Lisboa, Ulmeiro, 1990.

10 John Maynard Keynes, General Theory of Employment, Interest, and Money, 1935, ed. online de The University of Adelaide:

http://ebooks.adelaide.edu.au/k/keynes/john_maynard/k44g/chapter24.html\#chapter24 
Como citamos já em exergo, Flusser assim coloca a questão, e o que diz tem muito que se lhe comente: “(...) não havendo mais autoridade e não havendo mais decisões a tomar, que sentido terá na sociedade telemática emergente falar-se em governo, em poder, já que tal sociedade será dominada pela imagem? Qual será a estrutura político-administrativa de tal sociedade?"11.

\section{QUESTÕES CONSTITUCIONAIS, CONCEITUAIS E HISTÓRICAS}

\subsection{Chefes, heróis, salvadores: substitutos da Cidadania}

Uma das principais características do Estado Constitucional é a poliarquia, a pluralidade dos poderes e a sua separação ${ }^{12}$. Tal é, evidentemente, uma das mais eficazes garantias da efetivação dos Direitos Fundamentais e da subsistência de uma Democracia. Porém, é muito complicado (e inoportuno) indagar se uma sociedade informacional plena ainda será, deveras, uma Democracia.

Pelo menos as democracias estão em crise. Mais uma vez, espera-se ao menos que não a última (porque se espera que a Fenix democrática sempre venha a renascer). Nas crises das democracias, contudo, assoma sempre o complexo da tutela: ou do pai, ou "da governanta", ou afim... Os povos, que deveriam entender que a sua emancipação é irreversivel no plano do valor, infelizmente caem em abatimento e em descrença de si, e estão prontos a delegar tudo, mesmo os seus direitos mais inalienáveis, em tutores, que são considerados chefes, heróis, salvadores. É o regresso à menoridade. Essa menoridade que Kant consideraria superada com as Luzes, no seu imortal estudo Was ist Aufklärung: ${ }^{13}$

O Estado Constitucional fez-se e faz-se para que os destinos públicos sejam tomados coletivamente em mãos, e não repousem nas de messias políticos insubstituiveis até que sejam assassinados ou caiam das cadeiras do poder (metafórica ou literalmente). Contudo, é redobradamente importante, neste tipo de Estado, que existam elites demofílicas, e que neles também esteja presente o elemento unipessoal (a que alguns chamam "monárquico"), elementos próprios dos regimes mistos, definidos desde Aristóteles como os menos suscetiveis de corrupção.

11 Vilém Flusser, O Universo das Imagens Técnicas. Elogio da Superficialidade, p. 125.

12 V. ainda, classicamente, Franco Bassi, Il Principio della separazioni dei poteri (evoluzione problematica), (2. ${ }^{a}$ parte), in "Rivista Trimestrale di Diritto Pubblico", anno XV, 1965, p. 17 ss.; Manoel Gonçalves Ferreira Filho, Curso de Direito Constitucional, 21. a ed., São Paulo, Saraiva, 1994. Cf. os nossos livros Pensar o Direito, I. Do realismo clássico à análise mítica, Coimbra, Almedina, 1990, p. 223 ss., e Política Minima, 2. ${ }^{a}$ ed., corrigida e actualizada, Coimbra, Almedina, 2005, p. 143 ss..

13"Aufklärung ist der Ausgang des Menschen aus seiner selbstverschuldeten Unmündigkeit. Unmündigkeit ist das Unvermögen, sich seines Verstandes ohne Leitung eines anderen zu bedienen. Selbstverschuldet ist diese Unmündigkeit, wenn die Ursache derselben nicht am Mangel des Verstandes, sondern der Entschließung und des Mutes liegt, sich seiner ohne Leitung eines andern zu bedienen. Sapere aude! Habe Mut, dich deines eigenen Verstandes zu bedienen! ist also der Wahlspruch der Aufklärung."http://www.prometheusonline.de/heureka/philosophie/klassiker/kant/aufklaerung $\underline{. \mathrm{htm}}$ 
Um Estado constitucional precisa de ser governado normalmente por todos (eleições gerais, parlamento representativo), em alguns casos pelos mais preparados (juízes, membros do governo - ao menos em teoria), e em situações limite por um único, não livre das leis e do conselho, mas seu primeiro servidor (primeiro-ministro, presidente da república / rei). É difícil haver Estado com separação dos poderes que não tenha estes diversos elementos. No seu equilíbrio está a chave da estabilidade política, da boa representação e do bom governo.

\subsection{O Constitucional}

O salvador que alguns pretendem ou é apresentado e assumido como um puro e simples ditador, ou ainda se embrulhará sob a forma de uma "chefia constitucional". Poderá haver chefe constitucional, mesmo? Temos que começar por recordar o que seja essa qualidade de "ser constitucional”...

"Constitucional" remete, naturalmente, para "Constituição". Contudo, se adotarmos um conceito vasto (embora absolutamente rigoroso) de Constituição, o problema do chefe constitucional fica um tanto sem sentido. Na verdade, segundo o conceito histórico-universal de constituição, que foi apercebido por Lassale, na sua célebre conferência Über Verfassungswesen ${ }^{14}$, e depois repetido certamente na maioria dos manuais e tratados de Direito Constitucional pelo mundo fora, em todos os tempos, todos os povos, sempre, onde há politica, onde há poder social, público, há Constituição. Ora, um chefe constitucional seria, por esta ordem de ideias, todo o chefe político, porque sempre há uma Constituição.

Quando nos lembramos de Aristóteles e da sua "Constituição de Atenas", devemos recordar que ele e a sua equipa percorreram a Hélade a recolher as constituições de dezenas e dezenas de cidades-Estado15). É óbvio que nenhuma delas se encontrava sistematizada ou sequer compilada em edição com esse nome. Como aliás, hoje em dia, o Tratado de Lisboa, sendo constituição europeia, conjuntamente com outras fontes, é uma constituição sui generis, mas não o deixa de ser, para o ente político União Europeia ${ }^{16}$.

Mas parece óbvio que não é disto que se trata, antes deveremos tomar "constitucional" num outro sentido, mais específico. Depende é até onde levaremos a especificidade.

A doutrina jurídica dominante parece ter relutado de algum modo em fazer aplicar o conceito histórico-universal de constituição à história constitucional nacional e até internacional, parecendo por um momento que esse conceito se poderia aplicar na Papuásia ou na Patagónia, mas não no próprio país, em que o Constitucionalismo (e esse conceito e as questões que em seu torno se levantam

${ }^{14}$ Ferdinand Lassale, Über Verfassungswesen, trad. port., O Que é uma Constituição Politica?, Porto, Nova Crítica, 1976.

15 A tradução de Saramago da monumental obra de André Bonnard, Civilisation Grecque, trad. port. de José Saramago, A Civilização Grega, Lisboa, Edições 70, 2007, pp. 19-20, fala em "cidadecantão", e alude a uma "forma cantonal do Estado".

16 Mais desenvolvimentos no nosso Do Primado da Constituição ao Tratado de Lisboa - Ensaio sobre as Fontes do Direito, in "Interesse Público" número 52, Belo Horizonte, Editora Fórum, 2009, pp. 115-145. 
são da maior importância ${ }^{17}$ ) seria sobretudo um movimento jurídico-político, com primeiras erupções na Inglaterra do séc. XVII e sobretudo nos EUA e na França do séc. XVIII. O que estaria, então, antes do séc. XVII? Não haveria Constituição? Claro que havia, na perspetiva lassaleana, do conceito histórico-universal de constituição.

Assim, hoje parece mais pacífico, que houve duas grandes fases até à atualidade: a primeira, de constitucionalismo chamado histórico, natural, tradicional ou material (ou nomes afins), em que as Constituições não são voluntaristas, nem codificadas, mas emanam do jogo natural de forças de poder nas respetivas sociedades, podendo apenas ter positivações escritas, mas esparsas; e a segunda, na senda do referido movimento constitucional moderno, em que de forma sistemática, científica e sintética se procura codificar o direito político, de maneira voluntarista, criando livros em que articuladamente se apresenta a ordem politica e mesmo social de um Estado, ou entidade afim.

Hoje em dia, sob o impacto de doutrinas não jurídicas agressivas e até certo ponto "dominantes" (ideologia dominante), alguns juristas estão a receber teorias de descodificação e de desconstitucionalização, e as constituições ainda formalmente vigentes, confrontadas com a crise economica e financeira, não encontraram ainda juristas e politicos capazes de eficazmente as defender, pelo que se teme que nos encontremos numa terceira fase, de recuo do constitucionalismo moderno, em que as metanarrativas (há certamente um fantasma do Pós-moderno de Lyotard, mesmo em quem não o leu diretamente) e programas constitucionais ou acabem por ser exilados dos textos constitucionais, ou aí permaneçam como simples fórmulas decorativas e caducas a que a política e os tribunais não prestem atenção.

Neste contexto, não devemos considerar chefe constitucional nem o chefe dos tempos de constitucionalismo histórico, sob pena de a todos termos de considerar, nem o chefe dos tempos atuais, ou em prospeção para um futuro que se adivinha de "chefes", porquanto a demagogia crescente normalmente gosta de acolher a sua menoridade cívica à sombra de algum bafejado pela sorte ou pelo azar, normalmente muito cheio do seu ego, e que acredita, ou quer fazer aos outros acreditar, no caráter salvífico da sua pessoa e das suas ações. Com efeito,

17 Sérgio Resende de Barros, Contribuição Dialética para o Constitucionalismo, Campinas, SP, Millennium, 2007; J. M. Cardoso da Costa, Constitucionalismo, in "Polis. Enciclopédia Verbo da Sociedade e do Estado“, Lisboa, Verbo, 1983, I vol., col. 1151 ss.. Desenvolvimentos críticos, v.g., de Pietro Giuseppe Grasso, El Problema del Constitucionalismo después del Estado Moderno, Madrid / Barcelona, Marcial Pons, 2005. Recordando alguns cotejos relevantes, antigos e modernos, de entre inumeráveis : Charles Howard Mc Ilwain, Constitutionalism - ancient and modern, revised ed., Ithaca, New York, Cornell Univ. Press, 1974; Luiz de Magalhães, Tradicionalismo e Constitucionalismo. Estudos de História e Politica Nacional, Porto, Lelo [sic], 1927; Luís Prieto Sanchís, Constitucionalismo y Positivismo, México, Fontamara, 1997. 
clama-se nos tempos atuais, numa contraditio in terminis que seria divertida se não constituísse sinal dos tempos, que a solução política passaria não por um único chefe de mão dura, mas por vários: não um Salazar (aliás votado o português mais popular em concurso televisivo, seguido do histórico líder comunista Álvaro Cunhal - o que explicará o caráter altamente militante do voto em ambos ${ }^{18}$ ), mas um punhado de "salazares"... Faz parte da tópica desse abrómetro da sociedade urbana de hoje que são os taxistas, e como foi advertido pelo sociólogo Paavo Usitalo.

\subsection{Os Chefes}

Quanto aos chefes, a clássica abordagem é, como é sabido, a que podemos colher em Max Weber ${ }^{19}$, e que sempre dá frutos.

Mas há que ver o contexto, antes de mais. A sociedade portuguesa, que não soube superar o atraso em que se foi perdendo, na corrida desenfreada da modernidade ${ }^{20}$, hoje saindo de profunda crise de abatimento nacional e perigo para o regime democrático ${ }^{21}$, mas ainda em considerável momento de desesperança com a classe política, indignada com mordomias de uns a par de austeridades pesadas de outros, e constantes faltas às promessas, iludidamente vibrando com o futebol e pouco mais, dá claramente sinais perigosos de não acreditar em legitimidades tradicionais ou patriarcais, que não reconhece nem sequer vislumbra, descrê cada vez mais perigosamente das legitimidades modernas eleitorais (como avança a tese de doutoramento em ciência política de Mário Nuno Neves ${ }^{22}$ ), e parece infelizmente ainda muito aberta à possibilidade de um chefe do carismático, bonapartista ou outro ${ }^{23}$. Apesar de haver motivos de esperança, com a recuperação da confiança nos últimos tempos, e indicadores económicos (naturalmente a tal associados) a considerar positivamente.

A única alternativa a uma chefia deste tipo é a governação que prescinda da fórmula voluntarista e concentradora do poder num só (ou para isso tendendo), que só se consegue em estados reduzidos, como nas cidades-estado gregas ou

18 Jornal "Público", 26 de março de 2007: http://www.publico.pt/Media/salazar-eleito-omaior-portugues-de-sempre-em-programa-da-rtp-1289390 (consultado em 4 de novembro de 2012).

19 Max Weber, Wirtschaft und Gesellschaft. Grundgriss des verstehenden Soziologie, trad. ingl., Economy and Society, Berkeley..., University of California Press, 1978, 2 vols.. , vol. I, p. 212 ss..

20 Recordemos, por todos, Antero de Quental, Causas da dos Povos Peninsulares, cit., Fernando Pereira Marques, Sobre as Causas do Atraso Nacional, cit..

21 V. já o testemunho do internacionalmente renomado filósofo José Gil, Portugal, Hoje. O Medo de Existir, 3. ${ }^{a}$ ed., Lisboa, Relógio D'Água, 2005 (1. ${ }^{a}$ ed. 2004). Aludindo nomeadamente a "baixo grau de cidadania e de liberdade" (p. 41), "ameaças à liberdade de expressão" (p. 127), "quão frágil é a nossa democracia" (p. 139).

22 Mário Nuno Neves, Fundamentos e Determinantes da Implantação e Evolução do Sistema Político da III República Portuguesa, cit.. Sobre esta tese, o nosso Os Cidadãos e o Sistema Politico: Identificação ou Descontentamento?, "Revista Internacional d'Humanitats”, vol. XV, n. ${ }^{\circ} 25,2012$, pp. 71-80.

23 Em geral, sobre as teorias mais recentes neste âmbito, cf. Antonio Carlos de Almeida Diniz, Teoria da Legitimidade do Direito e do Estado. Uma Abordagem Moderna e Pós-Moderna, São Paulo, Landy, 2006. 
nos cantões suíços (e daí Rousseau, que pouco acreditava na representação, cantar loas à sua Pátria helvética), ou então, em estados maiores, pela criação de escol ou elite que, de forma colegial, seja capaz de bem gerir a coisa pública.

É sintomática da perda de confiança na fórmula democrática e pluralista, pelo menos ao nível da democracia civil, nas entranhas reais da sociedade, e independentemente da manutenção do estado democrático ao nível das macroestruturas do Estado (desde logo, dos órgãos de soberania políticos) a legislação, nacional ou a regulamentação local que sistematicamente substituem conselhos por diretores ou presidentes singulares. E isso está a ocorrer em vastos setores da sociedade, de há alguns anos a esta parte, com uma ideia importada das áreas da Gestão e Administração, mas obviamente não sem conteúdo ideológico: a de que o coletivo é incapaz de governar, e só o chefe forte e tendendo para o poder ilimitado é capaz de pôr as coisas a funcionar e de assim as manter. $\mathrm{O}$ preço a pagar, e que alguns já pagam diuturna e amargamente, é a arbitrariedade pessoal do chefe, a qualquer nivel. Claro que há chefes esforçados, abnegados, até capazes de ouvir os outros. Mas esses não são chefes políticos, são santos provisoriamente em lugares de mando, que a seguir virão a ser ocupados por vorazes predadores. E há poucos santos e que resistam às investidas dos pasicopatas do poder. Aliás, por exemplo em Mentes Perigosas, a psiquiatra Ana Beatriz Barbosa Silva já explicou como a chefia política é um dos mais apeteciveis lugares de ação de doentes mentais sem escrúpulos, sem remorsos e sem cura. E traça-nos um panorama que poderá ser assustador: "A grande maioria dos psicopatas utiliza suas atividades profissionais para conquistar poder e controle sobre as pessoas. (...) Muitos se camuflam em pessoas responsáveis através de suas profissões. Nesse contexto, podemos encontrar policiais que dirigem redes de prostituição, juízes que cometem os mesmos delitos que os réus - mas no julgamentoos condenam com argumentações jurídicas impecáveis. Banqueiros que disseminam falsos boatos econômicos na economia. Também alguns lideres de seitas religiosas, que abusam sexualmente de seus discípulos, ou ainda politicos e homens de Estado que só utilizam o poder em proveito próprio. Estes últimos costuma representar grandes perigos pelo tamanho do poder que podem deter" 24 .

Não curaremos, assim, dos tempos atuais, em que mil e um tiranos e tiranetes 25 adora e aspiram aguerridamente à liderança. Não liderança demofílica, ao menos, mas liderança em proveito próprio. A observação empírica do micro-social e do micro-político é já suficientemente eloquente sobre o que seria (v.g. em Portugal) um Estado, por exemplo, presidencialista, em que o chefe do Estado e o chefe do Governo se identificassem, e pior ainda se (como tudo indicaria) fossem apoiados ou por uma maioria no Parlamento, ou nem houvesse, realmente, controlo parlamentar algum. Basta acompanhar medianamente a comunicação social, que de tempos a tempos surgem propostas inconstitucionais de revisão constitucional ${ }^{26}$ nesse sentido, ou então de restauração da Monarquia.

24 Ana Beatriz Barbosa Silva, Mentes Perigosas, Rio de Janeiro, Fontanar, 2008, p. 101.

25 Maria Luísa Malato, Manual Anti-Tiranos, Porto Alegre, Livraria do Advogado, 2009.

26 Contudo, há regras estritas para as revisões, sob pena de revisões constitucionais inconstitucionais. Cf., em geral, José Joaquim Gomes Canotilho, Rever ou Romper com a Constituição Dirigente? Defesa de um Constitucionalismo Moralmente Reflexivo, São Paulo, Instituto 
Nem sempre se desejando (embora maioritariamente sim) uma nonarquia democrática e parlamentarista.

\subsection{Politicos e Estadistas}

Há uma diferença profunda entre o Estadista e o político, mesmo o político honesto, cumpridor e até talentoso. É a chispa do génio que àquele distingue.

Da mesma forma que é nocivo a um vero criador ter modelos estéticos (recordemos, por exemplo, o que na sua Memória Pessoal afirma um Antoni Tàpies ${ }^{27}$ ), a um Estadista é péssimo ter modelos politicos, e mais ainda dogmas.

Os grandes, nas Arte como na Política (que outra Arte é), traçam o seu próprio caminho. São eles próprio modelos, não cópias. Quanto mais procuram ser bons alunos, os politicos que procuram a imitação e o seguidismo mais se afundam no não serem. Porque ninguém realmente consegue ser uma fotocópia de outrem, nem uma simples encarnação de uma ideologia de cardápio. E daí que algumas figuras, na arte como na politica, soem a falso. Porque o seu ser pessoal é abafado pela máscara que escolheram. São uma espécie de ventríloquos.

A reprodução mecânica e as suas influências na arte e na sua perceção foram pioneiramente analisadas por Walter Benjamin ${ }^{28}$. Temos muito a aprender com essas reflexões. Um mundo de democracia telecomandada, de objetos em série, é, também, queiramos ou não (e há certamente quem queira) um mundo de consumidores em série, estereotipados, e de pessoas em cadeia, em série, sem personalidade própria.

\section{III.TEMPOS E TEMAS}

\subsection{Delimitação Temporal}

O regime constitucional é definido de forma muito clara e emblemática pelo art. 16 da Declaração dos Direitos e do Cidadão, francesa: "Toute Société dans laquelle la garantie des Droits n'est pas assurée, ni la séparation des Pouvoirs déterminée, n'a point de Constitution.".

Este pequeno texto consubstancia a mudança de paradigma dos tempos das constituições naturais, históricas, não codificadas, para o das constituições modernas. Ora se já vimos que as primeiras não podem entrar no nosso presente estudo (e na sua vigência sem dúvida poderíamos encontrar muitos chefes, mas

Brasileiro de Direito Constitucional, Senado Federal, 1999; Jorge Miranda, Sobre os Limites Materiais da Revisão Constitucional, "Revista Jurídica", n. ${ }^{\circ}$ s 13 /14, 1990; Idem - Acabar com o Frenesim Constitucional, Separata do volume colectivo Nos 25 Anos da Constituição da República Portuguesa, Lisboa, Associação Académica da Faculdade de Direito de Lisboa, 2001. E mais recentemente, com vasta apreciação de propostas revisionistas, o nosso Constituição \& Politica, cit., passim.

${ }^{27}$ Antoni Tàpies, Memòria personal. Fragment per una autobiografia, Editorial Critica, 1977, trad. do catalão por Javier Rubio Navarro / Pere Gimferrer, Memoria Personal. Fragmento para una Autobiografia, Barcelona, Seix Barral, 1983, máx. p. 13 ss., p. 375 ss..

28 Walter Benjamin, "The work of Art in the age of mechanical reproduction", in Illuminations, com uma Introdução de Hannah Arendt. Trad. de Harry Zohn, Ed. de Londres, Fontana Press, 1992, p. 211 ss.. 
não especificamente notáveis por serem "constitucionais" - apenas, em geral, convivendo naturalmente com a Constituição natural do seu tempo), quanto às segundas importa precisarmos alguns pontos ainda.

Antes de mais, quanto à tópica eterminante da existência de uma constituição moderna, este artigo explicitamente nos remete para dois: os Direitos (depois ditos fundamentais, humanos, etc.), e a Separação dos Poderes. A que - extra-texto e garantindo-o - se acrescenta a própria sacralidade da constituição codificada, que passa assim a ter uma tríade definidora.

Pois bem. Embora a separação dos poderes possa não ser na prática, ou até no texto de certas constituições perfeita, e pese embora que a garantia efetiva dos grandes direitos possa também não ser completa em certos casos, o facto é que há uma suficiente opinião que concordará que, por exemplo em Portugal, tivemos este constitucionalismo moderno, com separação dos poderes e direitos (ora mais, ora menos, claro), de 1822 a 1926, ou seja, desde a Constituição liberal monárquica até ao golpe de Estado militar que poria fim à I República, sendo a separação dos poderes e os direitos só recuperados com a revolução do 25 de Abril de 1974, mantendo-se essa situação até o presente.

Tal significa que o chefe constitucional, ou os chefes constitucionais a procurar, pelos dados do problema, só poderiam buscar-se nesses dois períodos, separados entre si pelo Estado Novo, que não foi nem República nem Estado constitucional, apesar de ter plebiscitado, num acto muito contestável, uma constituição autoritária, e mesmo assim em grande medida infetiva, nominal, ou seja, desrespeitada na prática pelos abusos do poder.

Se utilizarmos, então, um sentido forte de "constitucional", e entendermos que por chefe se fala numa liderança pessoal e forte, com algo de carismático, ficamos em alguns apuros sobre o que possa ser um "chefe constitucional". Porque precisamente a forma de governo, sistema, regime constitucional (as nomenclaturas são totalmente dispares de autor para autor ${ }^{29}$ ), procurando o governo das leis e não dos homens, parece ter no seu seio precisamente a contradição com a própria ideia de um chefe.

\subsection{Delimitação do objeto}

Compreendendo-se nesta obra vários tipos de chefes que poderiam, de algum modo, concorrer ou confluir ou confundir-se com chefes constitucionais, devemos compreender que eles podem ser também chefes constitucionais (como o liberal, o republicano, etc.) mas o que aqui especificamente importa é, além da liderança, certamente - a qual tem de ser de um certo tipo -, o facto de a sua chefia estar impregnada de Constituição, ou de ter sido relevante para o triunfo de uma Constituição.

Nesse sentido, cada constituição portuguesa (das verdadeiras, em sentido rigoroso: não cartas constitucionais ou documentos autoritários plebiscitados, como o texto de 1933) tem o seu chefe constitucional. Não teríamos muitas

${ }^{29}$ Cf. Ricardo Leite Pinto / José de Matos Correia / Fernando Roboredo Seara, Ciência Política e Direito Constitucional. Teoria Geral do Estado e Formas de Governo, $3 .^{\mathrm{a}}$ ed. - revista e ampliada, Universidade Lusíada Editora, 2005, pp. 199-200. 
dúvidas de que o grande chefe constitucional da Constituição de 1822 foi Manuel Fernandes Tomás. Era desassombrado, e por isso morreu pobre, e não durou para ver desvirtuada a Constituição por que lutou. Pode dizer-se que se finou com a sua conclusão. Além disso, era um patriota e um iconoclasta.

Um dia, numa viva polémica contra Borges Carneiro, a propósito dum ponto que constava da constituição espanhola e que ele não aceitava senão num código judiciário, Fernandes Tomás, provavelmente irritado com tanto servilismo em relação a Espanha (lembramos como tinha despedido os conspiradores espanhóis que lhe haviam proposto o iberismo), pôs os pontos nos "ii": [...] nem por estar na constituição espanhola essa especificação constitui artigo de fé [...]. A Constituição espanhola não é um evangelho. Eu sou português e estou aqui para fazer uma Constituição portuguesa e não espanhola"30

A Carta Constitucional tem dois chefes, um politico-militar, que é o próprio rei D. Pedro IV (o Imperador D. Pedro I do Brasil), e outro, mais silencioso, mas vital para a implantação desta Constituição sui generis (pois foi outorgada pelo monarca), o grande legislador o jurista e estadista Mouzinho da Silveira.

Não se pode conceber a Carta Constitucional sem a personalidade de D. Pedro. Ela é muito sua criação, mesmo que tributária de outras influências reconhecidas. Porque sem D. Pedro não haveria Carta. É o ato dum homem, o único homem que podia fazê-la, embora ele de algum modo, assim, encarne a volonté générale. A prová-lo, a enorme longevidade desta sua criação: que com breves intervalos (entre os quais a Constituição de 1838) vigoraria de 1826 a 1910.

Se D. Pedro é uma figura romântica, libertador de dois países (como Lafayette fora o "herói dos dois mundos", mas que morre cedo, dir-se-ia sem ver a sua "Jerusalém"), já Mousinho da Silveira, meticuloso demolidor do Ancien régime português, seria considerado o "Moisés do liberalismo". Tal epíteto assim foi explicado: "É-o não tanto pelo brilho ou pela espectacularidade da sua carreira não foi um herói no sentido corrente do termo (...) Um herói ((foi)) pela inteligência, pelo carácter, pela modéstia, pela desambição, pela espantosa obra legislativa de que foi autor"31.

A Constituição setembrista, de 1838 não pode deixar de ter como seu líder o advogado e grande tribuno parlamentar Manuel da Silva Passos, conhecido por Passos Manuel.

São já vários vultos para o liberalismo. Depois de Passos Manuel é mais complexo encontrar um chefe ao mesmo tempo constitucional. Numa nota autobiográfica um dos possiveis escolhifos, José Luciano de Castro, não deixa de falar em chefes, e até em "caudilhos", o que é sinal de pouca constituição ${ }^{32}$.

30 Joaquim de Carvalho, A Obra Legislativa das Cortes, pp.101-102.

31 António de Almeida Santos, Mousinho da Silveira, o "Moisés do Liberalismo" Português, in "Notandum", n. ${ }^{\circ}$ 22, jan-abril, São Paulo / Porto, 2010, pp. 13-20; Idem - Nova Galeria de Quase Retratos, Lisboa, Campo da Comunicação, 2011, p. 177.

32 "dezanove anos eu era advogado e legislador. Deputado desde 1854 e par do reino vitalício, não me recordo bem desde que data, encontro-me, actualmente, aos setenta e dois anos de idade, tendo sido cinco vezes ministro e três presidente do conselho, sem a menor ambição, com o único 
Um defensor da Constituição Republicana? Decerto Afonso Costa seria uma escolha sedutora, para o bem e para o mal... Figura polemíssima, idolatrado e odiado, também ele tem um destino de antiherói, acabando por, ao contrário do que se propala e mesmo crê, nem ter chefiado tanto tempo assim o Governo (recusou várias vezes chefiá-lo por falta de condições), e depois havendo-se retirado para Paris, onde morreu novo e onde seria inicialmente enumado.

E da Constituição de 1976? Dada a proximidade temporal do período constitucional pós-25 de Abril, não nos embrenharemos por essas considerações. Seria possivel contudo encontrar um defensor da nossa atual Constituição (de 1976), hoje praticamente posta entre parêntesis, salvo na descarnada dimensão estrutural política (o funcionamento formal e superestrutural da democracia) e um esboço de "prova de vida" no Ac. 353 / 2012, do Tribunal Constitucional. Como coletivo, esse defensor da Constituição deveria ser o Tribunal Constitucional. Mas não é de coletivos que se trata quando se fala em "chefe", que quase beira o "herói".

As instâncias de controlo da constitucionalidade são garantes da Constituição. E sempre recordamos a observação de Manoel Gonçalves Ferreira Filho, pela qual se torna claro que a distinção entre certos conceitos do Direito Constitucional não é um simples jogo do espírito: "A distinção entre Constituição rígida e Constituição flexível, entre Poder Constituinte originário e Poder Constituinte derivado, implica a existência de um controle de constitucionalidade. De fato, onde este não foi previsto pelo constituinte, não pode haver realmente rigidez constitucional ou diferença entre o Poder constituinte originário e o derivado. Em todo Estado onde faltar controle de constitucionalidade, a Constituição é flexível: por mais que a Constituição se queira rígida, o Poder Constituinte perdura ilimitado nas mãos do legislador. Este, na verdade, poderá modificar a seu talante as regras constitucionais, se não houver órgão destinado a resguardar a superioridade desta sobre as ordinárias. Mais ainda, órgão com força bastante para fazê-1o." 33

desejo de que me deixem descansar e de que o Rei não me confira o pesado encargo da sua confiança para constituir governo. Fui, pela primeira vez, ministro da justiça em 1869, e, depois, ministro do reino em 1879, e presidente do conselho de ministros em 1886, em 1897 e em 1904. Sou o único politico sobrevivente dos que governaram, dos que estiveram à frente de governos no reinado de D. Luís. Daqueles homens eminentes, em cujo exemplo aprendi, nenhum resta. Todos eles passaram, deixando o rasto luminoso dos seus periodos de grandeza e de poder: Fontes Pereira de Melo e Serpa Pimentel, no partido regenerador; o duque de Loulé e Anselmo Braamcamp, no partido progressista. Todos estes quatro foram chefes, foram caudilhos e os seus actos estão impressos na minha memória com respeito e admiração. Por morte de Braamcamp, sucedi-lhe na chefia do partido progressista. Dava-se isso em 1885 e em 1886 era eu chefe de governo, presidente de um ministério de homens ilustres e notáveis, dos mais preclaros politicos que existiam no país. Mariano de Carvalho, no ministério da Fazenda; Emídio Navarro, no ministério das Obras Públicas; Barros Gomes, no ministério dos Negócios Estrangeiros, auxiliaram-me na minha obra e, conquanto houvesse depois modificações no gabinete, foi essa uma época de glória e de prosperidade para a monarquia. Estive no governo quatro anos e meio, até que o ultimato de Inglaterra atirou com tudo a terra. Não é este o momento de falar disso. A história fará justiça ao nosso patriotismo, e, na realidade, já a está fazendo" - Entrevista reproduzida em Correio da Noite, Lisboa, 27 de julho de 1907.

33 Manoel Gonçalves Ferreira Filho, Curso de Direito Constitucional, 17. ${ }^{\text {a }}$ ed., revista e 


\subsection{Antiheróis?}

Enquanto as sagas dos chefes são de afirmação, o constitucionalismo tem segregado antiheróis. Os chefes constitucionais são antiheróis. E isso de alguma forma se deve simbolicamente associar ao facto de que as constituições são realmente feitas para que possamos prescindir dos chefes, pessoas excecionais, mas muitas vezes também excecionalmente excêntricas, caprichosas, e muitas vezes pouco ou nada curando dos interesses dos seus concidadãos. Da ação do herói muitas vezes recolhe o povo algumas migalhas de glória e bem, mas é terrivel ter de verifcar que em muitos casos, embora as hagiografias e as martirologias digam o contrário, o problema do herói é ele mesmo. É contra si próprio e contra a fortuna que ele joga o seu jogo, sendo muito frequentemente o Povo um pretexto.

Ao contrário disso, o chefe constitucional é frequentemente um chefe apesar de si próprio, numa lógica de serviço, de chamamento superior. Mas o exercício da liderança é típico, e começa com o mito de Cincinatus: ele quer é voltar para a vida privada, uma vez posto o Estado minimamente em ordem, ou derrotados os inimigos.

Frequentemente este chefe, porque não é sedento do poder, abdica, retira-se, ou desilude-se, ou então continua de um ponto de mira privado a dizer o que pensa, certamente esperando que outros, mais novos e mais aguerridos, no terreno lhe continuem os passos. Frequentemente este chefe é, pois, um perdedor. Porque foi um idealista. E porque a realidade pós-revolucionária tende a engolir idealismos e a promover carreirismos, oportunismos, hipocrisias.

O verdadeiro chefe, herói e salvador constitucional é, se assim se pode dizer... a própria Constituição. É a ela que todos os protagonistas da República, a começar pelo presidente da República, têm de jurar. Porque ela é - ou deve ser - o protagonista da história constitucional. E assim não sendo, já se não estará em Estado constitucional.

Em contrapartida, a sociedade informacional, ao mesmo tempo que dá a ilusão da democracia informática, de um referendo permanente, pode estar a gerar, ainda que de forma inapercebida, novos fascismos, que serão protagonizados por personagens com características externas tecnocráticas (ou o contrário disso), mas seguem uma linha conhecida. Como afirma um avalizado conhecedor da matéria: "um líder carismático, populista, para mobilizar as massas; o seu próprio grupo é sempre vítima (das crises, da elite ou dos estrangeiros); e o ressentimento orienta-se todo para um 'inimigo. O contexto em que esta forma de política pode dominar é o de uma sociedade de massas afectada pela crise que ainda não aprendeu as lições do século XX"34.

atualizada, São Paulo, Saraiva, 1989, pp. 29-30. Cf. ainda, v.g., James Bryce, Constituciones Flexibles y Constituciones Rigidas, 2. ${ }^{a}$ ed. cast., Madrid, Instituto de Estúdios Políticos, 1962; Alessandro Pace / Joaquín Varela, La Rigidez de las Constituciones Escritas, Madrid, Centro de Estúdios Constitucionales, 1995; Francesco Rimoli, Costituzione Rígida, Potere di Revisione e Interpretazione per Valore, "Giurisprudenza Costituzionale", XXXVII, n. ${ }^{\circ}$ 5, 1992.

${ }^{34}$ Rob Riemen, De eeuwige terugkeer van het fascisme, trad. port. de Maria Carvalho, O Eterno Retorno do Fascismo, trad. port., Lisboa, Bizâncio, 2012, pp. 72-73. 


\subsection{Carisma e Irracionalidade na Sociedade da Informação}

O problema parece agravar-se consideravalmente, na medida em que esse novo totalitarismo (a que, confessamos produzindo algum choque para nós, muitos começam já declaradamente a chamar "fascismo": mas eles detetam perigosas similitudes), é feito ao mesmo tempo de populismo e demagogia com autorias e caudilhos, por vezes líderes locais que vão emergindo, e de uma massificação consumista e da sedução da imagem e dos meios informacionais, que paralizam a consciência e guiam os passos ou a inação.

Uns tranquilizarão as consciências perante o crescendo da irracionalidade em política (fundamentalismos vários) com o álibi da técnica e da tecnocracia, nomeadamente informacional. Os chefes anticonstitucionais não seriam senão epifenómenos.

Outros apaziaguarão os espíritos apontando precisamente a emergência de personalidades e de argumentos subjetivos ao mesmo tempo que as máquinas e as imagens pareceriam imperar.

Mas a confluência de dois males simétricos não é senão um sinal dos tempos. Como que a humanidade, à falta de espaço para se exercer, se volta para os tubos de escape de soluções preconceituosas ao máximo, obscurantistas, retrógradas, por não aguentar mais a assepcia e a plastificação de vozes de robot, de regulações sem fim, da sua própria robotização.

Se a ética se exila da politica por conta da pretensa cientificação do mundo, numa sociedade informatizada e informacional, a ideologia volta a galope, no pior de si, no mais selvagem e livre (libertino) da politica, na vontade de poder, na sede de sangue... Seria, segundo ainda Flusser "perfeitamente imaginável governo, regime, poer e domínio serem despidos de toda conotação político-ética, de toda ideologia"'35. Seria, sim. Mas entretanto, como que o petit peuple se vinga da máquina e da politica com seduções (mais nuns países que noutros). Parece que terá sido W. Reich quem escreveu (e ainda não pôde ver os novos movimentos como hoje são, tendo presente apenas o mais clássico): “O que é novo no fascismo é que as próprias massas consentiram em sua submissão e dedicaram-se a realizá-la"36.

As pretensões totalizantes (nas relações internacionais, militares, na administração, etc.) de que falava Armand Mattelart para a "revolução da informação"37 podem mesmo tornar-se totalitárias.

Imagine-se o que será se o fundamentalismo e o obscurantismo que acarreta conseguirem de forma eficaz assenhorear-se dos meios próprios da sociedade da informação. Por isso é que é um perigo para uma República, para um Estado Constitucional, um fanático com acesso fácil e dituturno aos meios de difusão em larga escala. E o que é mais simples, hoje, desde que se tenham meios financeiros para tanto?

\footnotetext{
35 Vilém Flusser, O Universo das imagens Técnicas. p. 126.

36 Apud M. Ansart-Dourlen, Freud et les Lumières, Paris, Payot, 1985, p. 204.

37 Armand Mattelart, Histoire de la société de l'information, Paris, La Découverte, 2001.
} 
Apenas a Educação para a cidadania, para a tolerância, para a convivência, desde logo fortemente fomentadas pelo Estado no seu pluralismo, apenas esses seriam os antídotos contra os extremismos que, juntando o lado mais obscuro e irracional, com uma racionalidade sem discernimento, podem fazer perigar séculos de sofrida construção da Liberdade e da Inteligência.

Enviado (submission date): 01/11/ 2016

Aceptado el (Acceptance Date): 03/01/2017 